\title{
Growth, Trade and Sustainability in the Spatial Economy
}

\author{
JEROEN C. J. M. VAN DEN BERGH \\ and \\ PETER NIJKAMP \\ Department of Spatial Economics, Free University \\ De Boelelaan 1105, $1081 \mathrm{HV}$ Amsterdam, Netherlands \\ Fax/Tel : +31-20-44460 05/97 E-mail : jvdbergh @ econ.vu.nl
}

\begin{abstract}
The interaction between environmental quality, economic activity and growth does not take place in a wonderland of no geographical dimensions, but is shaped in a mutually interacting spatial system of cities, regions and countries. Consequently, regional differences in land use, economic structure, consumption, technology and environmental policy incentives impact on the environmental sustainability of an interacting global-regional system. This paper addresses the issue of environmental quality in the context of economic growth in a non-spatial economy. Spatial economic dimensions have received relatively little attention in the debate on global change, long-run growth and international trade. The present paper deals with a formalization of spatial environmental quality, from a behavioural and policy perspective, and in particular with the relationship between economic performance and environmental sustainability of a multi-regional system. The analysis is - for the sake of illustration-based on a model of two interactive regions. These regions enclose a local economy and a local environment, which directly interact. The local economies are linked through trade, while the local environments are linked through the global environment. A wide array of numerical simulation results are presented that show developments of symmetric and asymmetric regions under various scenarios. Evaluation is based on summary indicators which may be considered to play the role of welfare variables. The approach here may be considered illustrative for a class of models that combine elements of economic growth theory, bioeconomics, general equilibrium theory and theories of policy coordination. Elements of a research agenda are presented in a concluding section.
\end{abstract}

\section{Growth and Environment in a Spatial Context}

The issue of environmental quality and long-run economic growth in a spatial or multiregional context has been largely neglected by economists. A short overview is given here of economic approaches to spatial dimensions of environmental problems, and particularly the combination of growth, trade and environment. Subsequently, a prototype dynamic simulation model is presented which can address some of the main questions related to 
growth and environmental quality in a multi-regional and global context. The model includes regional and interregional economic relationships such as production, consumption and trade, as well as interaction between the quality of local environments and the global environment. This adds a new dimension to single region growth models which cannot make a distinction between local and global systems.

The relationship between environmental quality and spatial economic processes is extremely important, but has until now not received very much focused attention from either regional or environmental economics (see Siebert (1985 and 1987)). There are, however, a number of traditional economic themes that indirectly relate to it ; firms' choice of location having an impact on spatial environmental quality (e.g., Markusen et al. (1993)) ; interregional and international trade affecting production and consumption related externalities (e.g., Anderson and Blackhurst (1992)) ; international coordination and negotiation in environmental policy planning, dealing with foreign trade, global environmental issues and transboundary pollution problems (e.g., Klaassen (1995)). Most spatial economic approaches adopt a discrete spatial perspective, using countries, regions or grid systems, and usually go along with a higher level of aggregation than in, for instance, physical geography and ecology (Klijn (1994)). Consideration of patterns of vegetation cover and economic use of land is essential to assess the environmental impacts of economic activity in general on the quality of the natural environment as well as its long term sustainability. Both in terms of localized and global interactions between economies and environmental resources insight must be obtained about the spatial overlap or closeness of economic amd environmental systems. Environmental economics has devoted relatively little attention to this perspective, and has focused on homogeneous or discrete space, often even narrowed down to a single point. In the context of particular sectors, such as agriculture and forestry, some attention has been given to spatial issues. With respect to agriculture diffuse pollution is much studied at the moment. Here, analytical approaches focus on information asymmetry and dynamic uncertainty (see Russell and Shogren (1993) ; and Dosi and Tomasi (1994)), while empirical studies deal mostly with spatial dispersion of pollution and land use scenarios, based, for instance, on Geographic Information Systems (e.g., Despotakis (1991)), and sometimes combined with multicriteria evaluation (e. g., Herwijnen et al. (1993) ; Beinat (1995)). Such methods have also been used to relate land use to landscape ecology (Maxell and Costanza (1994)). Land use has also implications for urban environmental quality and long run sustainability. On the receptor side of emissions land cover is important in terms of sensitivity of vegetation and potential effects of deposition of harmful substances such as sulfur. This has been approached by models with detailed information about spatial distribution of vegetation, soils and waters (e.g., Alcamo et al. (1990)).

The economic perspective is particularly relevant in sofar as it can shed light on the 
relationship between changes in locations and land use on the one hand, and in environmental quality on the other hand, via trade and related (passenger and freight) transport. The spatial structure of production, resources, extraction, consumer markets, infrastructure, housing and employment are essential in this respect. Few models have been able to simultaneously address these various aspects. In the context of a static spatial equilibrium model the link between trade, transport and spatial economy is addressed in Verhoef and van den Bergh (1996). The present paper adds a dynamic dimension to this, focusing on the interaction between interregional trade, economic growth and spatial and environmental dynamics and sustainability. In the next section the modelling of the interdependence between environmental sustainability on a regional scale and regional economic growth is discussed in more depth.

In Section 3 a model is presented that represents a two-region system, with trading economies, local environments and a global environment. The effects of growth, environmental policy, technology investment and technology diffusion are all considered in this model. This model combines elements of equilibrium trade theory, economic growth theory and environmental economics. In Section 4 results are presented of scenario analysis based on numerical simulation exercises performed with the above mentioned model. Two main cases are distinguished, namely a symmetric and an asymmetric two-region system in terms of technical conditions of production. The scenarios stusied incorporate growth, technological progress, technological diffusion and environmental policy. Section 5 offers some concluding remarks.

\section{Environment, Growth and Trade}

The potential conflict between environmental quality and economic growth is a topic which has attracted a lot of interest and generated much debate among economic growth theorists. For instance, neoclassical economic growth theory has frequently been applied to issues of renewable resource limits, long run pollution effects and sometimes even to a combination of these (see Tahvonen and Kuuluvainen (1991 and 1993)). Resulting analyses have focused on the role of substitution between man-made capital and natural resources materials in production, technological improvements in materials efficiency of production, and backstop technologies (see Dasgupta and Heal (1979)). The issue of sustainability has also been explicitly treated, although there is no agreement as to its theoretical interpretations (see, e.g., Toman et al. (1994)). Conservation-preservationist's and exploitationist's views are linked to the distinction between strong and weak sustainability (Pearce and Turner (1990)), with the Hartwick rule of investing resource rents in man-made capital as an extreme case of the latter (Hartwick (1977)). Modern growth theory has also been applied 
to environmental issues and sustainability (see Gradus and Smulders (1993); Bovenberg and Smulders (1994) ; Smulders (1994)) and in more "applied" long-run models of climate change economics (Nordhaus (1991 and 1993)). All these models do not simultaneously address spatial disaggregation, interregional trade and interaction between local and global environmental quality. The focus in the economic models nowadays is usually on endogenous technology and knowledge formation, mixing such positive externalities with nagative environmental externalities, and arriving at more optimistic conclusions than in neoclassical growth models with exogenous technology. The influence of pollution and preferences on thchnology choice is important in this respect. These results are often stated against conclusions obtained with global "limits to growth" models (Meadows et al. (1972 and 1992)). These lack advanced technology, price mechanisms, producers' and consumers' behaviour, and interregional trade submodels, and have therefore been heavily attacked by economists (e.g., Nordhaus (1973 and 1992)). Alternative approaches to the relationship between technology, growth and environment have stressed its evolutionary character (e.g., Faber and Proops (1990) ; Erdman (1993)). Whereas economists have been much concerned with the trade-off between economic (Pareto) efficiency and environmental sustainability, several other approaches focus on controllability (Perrings (1991)) and stability, the latter often based on ecological theory or metaphors (Holling (1986 and 1994)). Common and Perrings (1992) provide an interesting and systematic comparison.

The issues of regional and spatial sustainability have attracted relatively little attention, except maybe in the context of urban systems (Breheny (1992) ; Nijkamp and Perrels (1994)). One approach is to consider regions as open systems, both in terms of economic and environmental processes (e.g. Van den Bergh and Nijkamp (1991)). This has also been pursued in various in depth case studies (see Van den Bergh and Nijkamp (1994)). The other approach is to deal with multi-regional systems. Regional economics provides a rich perspective for theory regarding multi-regional dynamics (Anderson and Kuenne (1986)). Spatial price equilibrium theory has also been applied to questions of sustainability, mainly rlated to allocation issues in a spatial context (see Verhoef and Van den Bergh (1995)). More complex, but also theoretically more refined, are spatial general equilibrium models (Roson (1994)). Incorporating dynamics in such models is however a very difficult task. Finally, game theoretic models may be used to deal with specific questions of policy coordination (Van der Ploeg and De Zeeuw (1992)).

The approach adopted here to study economic growth and spatial environmental sustainability starts from the conception that spatial sustainability is a complex issue which can only be dealt with to its full extent in two- or multi-regional settings. Continuous spatial analysis may also be useful, but requires different and more tedious modelling, and would furthermore be less suitable for treating economic growth issues. In a multi-regional setting, 
the following important elements of spatial sustainability can be dealt with :

(i) imports in one region may cause unsustainable patterns in the respective region ;

(ii) imports in one region may cause unsustainable patterns in other regions via trade ;

(iii) exports in one region may cause unsustainable patterns in the respective region via trade ;

(iv) exports in one region may cause unsustainable patterns in other regions via trade ;

(v) environmental sustainability of one region is linked to that of other regions via the sustainability of the global environment.

Element (ii) may be referred to as "importing sustainability at the cost of unsustainability elsewhere". Elements (ii) and (iv) may be called "exporting unsustainability". Eelement (v) in combination with the dependence of regional production on regional environmental quality allows one to study the issue of spatial (interregional) environmental externalities.

\section{Modelling a Two-Region Economic-Environmental System}

We will first present now a simple illustrative model of two interactive regions. This model allows for tracting the mutual impact of changes in the global and local or regional environment, and the repercussions of these in terms of consumption, production and interregional trade. It may therefore be regarded as a prototype model of larger and more complex integrated climate-change/social-impact models. The model incorporates six main elements :

- production and consumption processes in the regional economies, and interrgional trade ;

- there is ex-ante (or intrinsic) growth of man-made production factors and the output of the regional economies, since the question is not what determines growth, but what is the long term environmental impact of a positive rate of growth, given that there exist mechanisms of technological progress and diffusion, consumption and international trade, and interaction between global and regional environmental quality ;

- regional environmental processes interact through the global environment, and are a link between generation and reception of environmental externalities ;

- endogenous technology allows for more efficient use of material resources in production ;

- there is diffusion of technology from region 1 to region 2 ;

- regional welfare aggregates indicators for consumption, and for regional and global environmental quality.

The different parts of the model are presented below ( $i$ denotes region $i ; i=1,2$ ). The functional specifications and numerical values adopted here reflect as much as possible choices consistent with theory and empirical facts. The behaviour of the system may 
therefore be considered quite realistic, although not directly related to, or based on, any specific multi-regional system. Without loss of generality, we have in the various equations already inserted the parameter values used for simulation. A list of definitions of variables is contained in the annex.

\section{Production}

Our specification of production relationships is very straightforward. Each region uses two regional inputs to produce output $Q_{i}$. The regional environment is one input $\left(E_{i}\right)$, i. e. it acts as a production condition, and the other input represents an aggregate of capital and labour $\left(K_{i}\right)$. The environmental inputs are externalities, as they cannot be directly chosen or influenced by the producers.

$$
\begin{aligned}
& Q_{1}=.3 K_{1}^{a 1} E_{1}^{b 1}, \\
& Q_{2}=.3 K_{2}^{a 2} E_{2}^{b 2},
\end{aligned}
$$

where $a_{1}+a_{2} \leq 1$. It is further assumed that the commodities represented by $Q_{i}(i=1,2)$ are different. This is formalized in the model by including consumption of each in the welfare function. As a result, trade between the two regions may develop.

In order to allow for eddogenous formation of trade patterns, regional production prices $\left(P_{i}\right)$ are determined per unit of output, based on the costs of the two inputs. The price of captital is chosen as the numéraire, while the price of resource materials $\left(R_{i}\right)$ is only positive when subject to environmental taxation $\left(t_{i}\right)$. The latter assumes that the use of nanural resource meterials is unpriced in a situation without environmental regulation. This may not hold for all types of resources, but is just chosen for illustrative purposes.

$$
P_{i}=\left(K_{i}+t_{i} R_{i}\right) / \operatorname{MAX}\left(1, Q_{i}\right)
$$

The MAX function is merely included to assure that the denominator is unequal to zero and prices are bounded from above.

\section{Consumption and trade}

In order to derive trade and consumption patterns, the following assumptions are made :

(i) Markets do clear ; in other words, production in each region is equal to total demand, comprising domestic consumption, export, investments $\left(I_{i}\right)$ and research and development $\left(I_{R \& D, 1}\right)$. The latter is assumed to only occur in region 1 , which may be regarded as a differential advantage, and is done so to be able to study spatial technological diffusion later on. Note that each country uses only its own output as an investment good, which may be realistic only for certain types of goods, or reflects independence or differences in development stages between countries. Later, technological diffusion is included to allow for more interaction in this respect on a level of knowledge exchange. $C_{i i}$ denotes the domestic consumption of commodity 1 , i.e. produced in region $i . C_{i j}$ is the import by region $i$ of 
commodity $j$, i.e. produced in region $j(i \neq j)$.

$$
\begin{gathered}
Q_{1}=C_{11}+C_{21}+I_{1}+I_{R \& D, 1}, \\
Q_{2}=C_{22}+C_{12}+I_{2} .
\end{gathered}
$$

(ii) Total trade flows in opposite directions are balanced. ${ }^{1}$

$$
P_{1} C_{21}=P_{2} C_{12} \text {. }
$$

(iii) A fixed coefficient $o_{1}$ indicates the degree of openness of region 1 .

$$
C_{11} / C_{12}=o_{1} \text {. }
$$

A large value of $o_{1}$ means a more closed system, a small $(<2)$ means a very open system, 1 means that imports equal domestic consumption. The fixed value of $o_{1}$, although not realistic perhaps for all countries, can be motivated for many countries by observing historical patterns. As the specific value is not important, $o_{1}$ is set equal to 2 here.

Rewriting of (4)-(7) gives the following reduced submodel for consumption and trade variables.

$$
\begin{gathered}
C_{12}=P_{1}\left(Q_{1}-I_{1}-I_{R \& D, 1}\right) /\left(o_{1} P_{1}+P_{2}\right), \\
C_{11}=o_{1} C_{12}, \\
C_{21}=P_{2} C_{12} / P_{1}, \\
C_{22}=Q_{2}-I_{2}-C_{12} .
\end{gathered}
$$

\section{Technology}

Only region 1 is assumed to perform research and development. This may be interpreted as region 1 being a more developed region, which contributes significantly more to technological progress than the other region. The state of technology $(T)$ in region 1 is improved by research and development $\left(I_{R \& D, 1}\right)$, in the following straightforward way.

$$
d T / d t=I_{R \& D, 1}, T(0)=0 .
$$

Technological progress reaches region 2 through diffusion $\left(T_{d}\right)$ with a certain time delay. This is set equal to 4 periods since its value is not essential, only that there is such a phenomenon. $d_{d}$ is a dummy variable indicating the rate of diffusion. Because of the time delay a historical pattern is necessary as an initial condition.

$$
T_{d}(t)=d_{d} T(t-4), T_{d}(s)=0, s=1,2,3 .
$$

The development of technology allows for more efficient resource use in production with an upper limit, as follows.

$$
\begin{aligned}
& R_{1}=.585\left(Q_{1}^{.8}((T+100) /(4 T+100)),\right. \\
& R_{2}=.585 Q_{2}^{.8}\left(\left(T_{d}+100\right) /\left(4 T_{d}+100\right)\right) .
\end{aligned}
$$

Parameter values were calibrated so as to generate realistic patterns.

\footnotetext{
${ }^{1}$ Note that combining equations (4) and (6) leads to the identity: $P_{1} Q_{1}=P_{1} C_{11}+P_{2} C_{12}+P_{1} I_{1}+P_{1} I_{R \& D, b}$ This may be regarded as a balanced budget relation (income=outlays) for region 1 . An analogous result holds for region 2 .
} 


\section{Growth}

Growth in both regions occurs via investment in the actors stock $K$, covering both physical capital and labour.

$$
d K_{i} / d t=I_{i}-D_{i}\left(K_{i}\right), K_{i}(0)=100 .
$$

Investment is considered a regional activity, and is restricted from above by regional production. When not limited, investment is at least equal to depreciation $\left(D_{i}\right)$, in which case the stock of actors remains constant. In the scenarios studied in the following section an ex ante net growth rate $g$ is considered, the value of which is set equal to $3 \%$. The reason for this was given at the opening of this section. The function MIN will translate this into an identical ex post growth rate as long as sufficient output is produced.

$$
I_{i}=\operatorname{MIN}\left(Q_{i}, D_{i}\left(K_{i}\right)+g K_{i}\right) .
$$

Depreciation occurs as a fixed proportion of the existing stock, and is set equal to $.05 K_{i}$.

\section{Environment}

The local environmental quality in each region is described by a logistic growth curve. The carrying capacity $\left(C_{c}\right)$ is set equal to 180 . The intrinsic regeneration (growth) rate of the renewable environment $(r(\bullet))$ is positively related to a global environment index $\left(E_{g l o b}\right)$. Resource extraction in region $i\left(R_{i}\right)$ causes the environmental quality in the region to decline.

$$
\begin{aligned}
d E_{i} / d t= & r\left(r_{g l o b}\right) * E_{i}\left(1-E_{i} / C_{c}\right)-R_{i}, E_{i}(0)=100 \\
& r\left(E_{\text {glob }}\right)=\operatorname{MIN}\left(E_{\text {glob }} / C_{c}, 1\right) * .2
\end{aligned}
$$

The $E_{g l o b}$ index represents the quality of the global environment, which is obtained by summing additive and multiplicative aggregation functions of the regional environmental indicators. In other words, if only one region has a low environmental quality this has severe implications for the global environment. However, only when both regions collapse the global environment will do so.

$$
E_{\text {glob }}=\left(E_{1} * E_{2}\right)^{.5}+.5 *\left(E_{1}+E_{2}\right)
$$

\section{Welfare}

Finally, welfare is calculated for each region, based on the consumption of each commodity, regional environmental quality, and the state of the global environment.

$$
W_{i}=C_{i 1}^{.6} * C_{i 2}^{.6} * E_{i}^{.4} * E_{\text {glob }}^{.2}
$$

This concludes the presentation of the model equations. Since it is an impossible task to derive the relevant analytical properties of this model, we will have to resort to simulation experiments. In the next section simulation results are discussed based on the above model specification. 


\section{Simulation Results}

In our simulation experiments we will in particular investigate the implications of different scenarios. The above model allows for a great number of scenarios to be studied. Each of these represents then a specific combinations of values for all paremeter and initial state variables. Recognizing this large potential of choices, the following six scenarios are considered in detail :

1. A symmetric economic system, i. e. identical production functions for both regional economies : $a_{i}=b_{i}=0.5, i=1,2$.

1. a. Ex ante net growth equals $3 \%: g=0.03$.

1. b. As 1. a, and with positive research and development : $I_{R \& D, 1}=5$.

1. c. As 1. a, and with environmental taxation : $t_{1}=20$.

2. An asymmetrical economic system : $a_{1}=b_{2}=0.2, b_{1}=a_{2}=0.8$.

2. a. Ex ante net growth equals $3 \%: g=0.03$.

2. b. As 2. a, and with positive research and development : $I_{R \& D, 1}=5$.

2. c. As 2. a, and with technology diffusion : $d_{d}=1$.

\section{Ad 1. a. Plain growth in a homogeneous world}

From Figure 1 one can see the homogeneity of the regions in the identical patterns of actors $\left(K_{i}\right)$ and production $\left(\operatorname{Prod}_{i}\right)$. The ex ante growth rate of $3 \%$ of actors initially translates into an identical ex post growth, but after time period 18 production starts to decrease until it becomes zero. When production is very low, investment $\left(I_{i}\right)$ decreases until it becomes zero, and the stock of actors starts to decrease. Note that the increase in capital does not translate into an increase of production. The reason for this is that the environmental input in

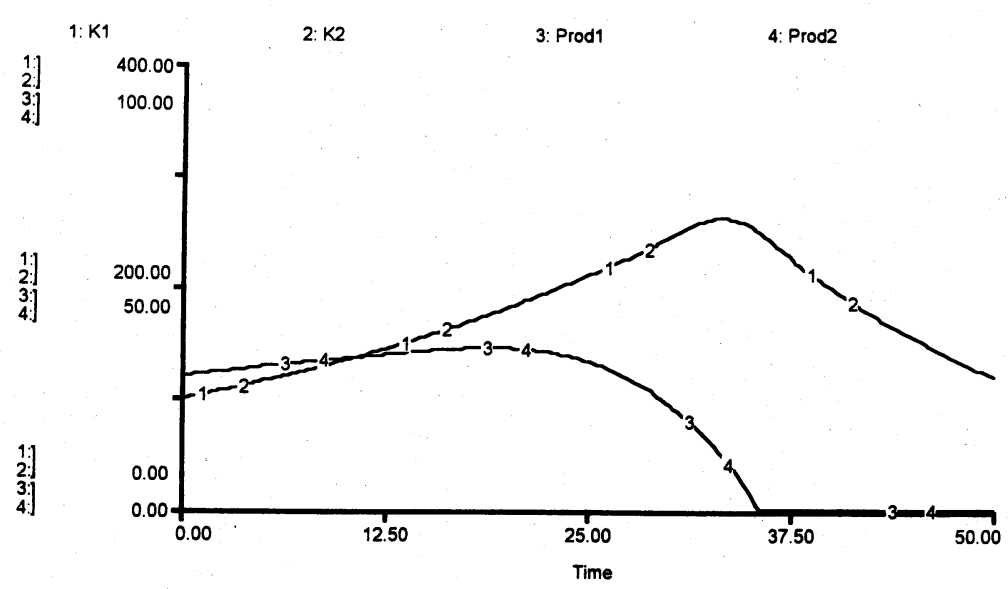

Figure 1. Scenario 1. a : Actors $\left(K_{i}\right)$ and production $\left(Q_{i}=\operatorname{Prod}_{i}\right)$. 
production, as a result of resource extraction, decreases in quality. This is shown in Figure 2 , where, again, the homogeneity of the regions can be seen from the identical patterns for regional environmental quality, implying the same pattern for the global environment. The homogeneity also means that the trade and consumption patterns are symmetric. This is shown in Figure 3.

\section{Ad 1. b. Environmental technology in a homogeneous world}

With fixed investment in environmental technology in region $1\left(I_{R \& D, 1}\right)$, interregional differential impacts are found in our spatial economic system. Comparing Figure 4 with Figure 1 shows that this strategy has positive impacts on the production in both regions, although

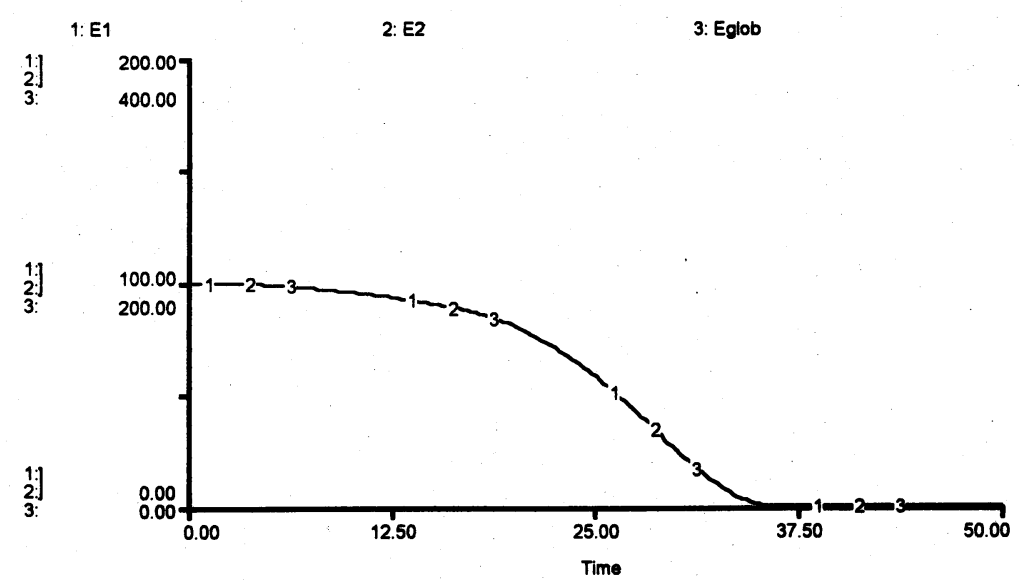

Figure 2. Scenario 1. a : Regional and global environmental quality $\left(E_{i}\right.$ and $\left.E_{g l o b}\right)$.

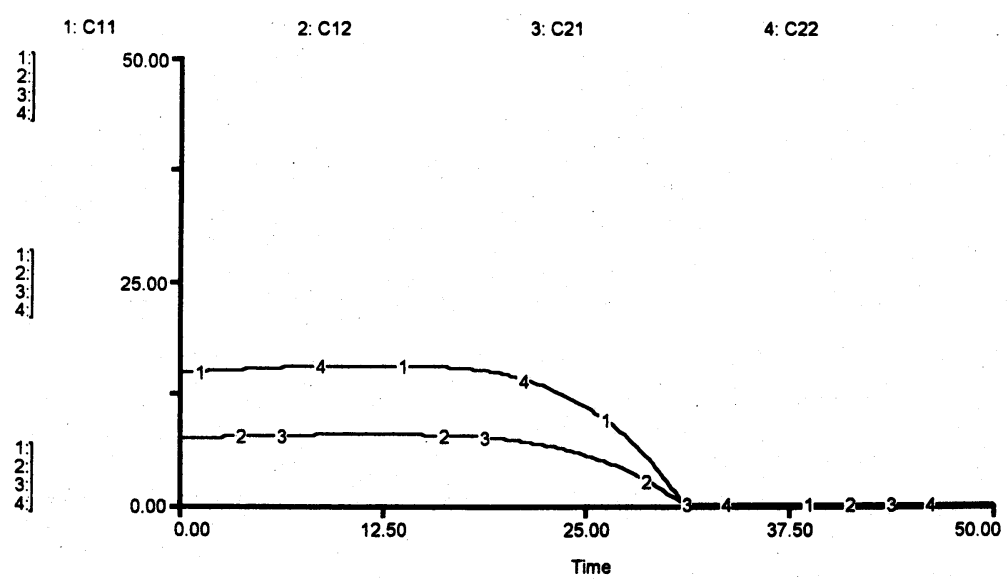

Figure 3. Scenario 1. a : Consumption $\left(C_{i i}\right.$ and $\left.C_{i j}\right)$ and trade $\left(C_{i j}\right)$. 
Growth, Trade and Sustainability in the Spatial Economy

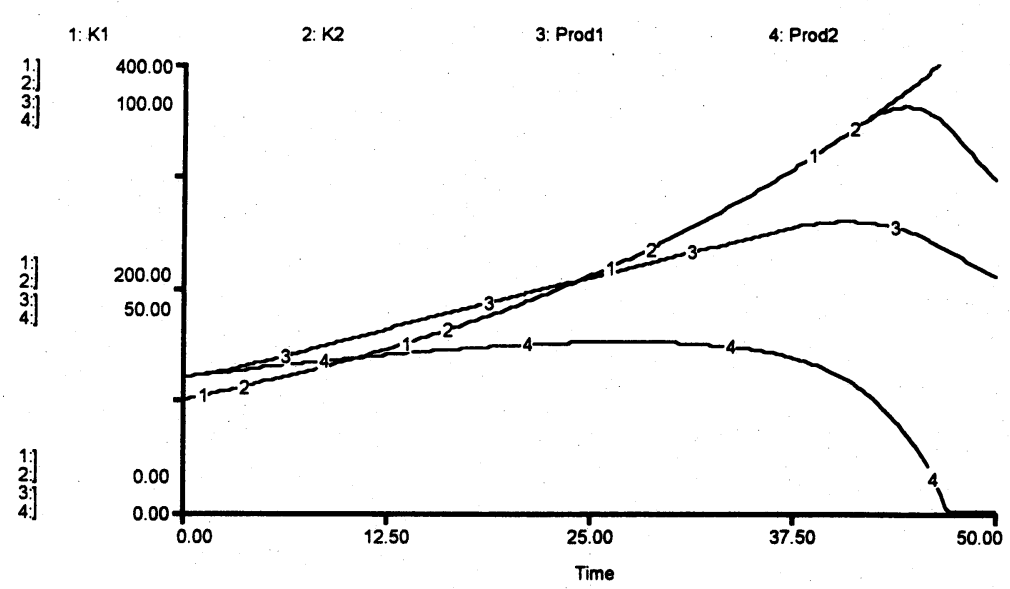

Figure 4. Scenario 1. b : Actors $\left(K_{i}\right)$ and production $\left(Q_{i}=\operatorname{Prod}_{i}\right)$.

clearly less so in region 2. Considering Figure 5, one can observe that the environmental quality in region 1 is improved relative to the initial position, whereas it is deterioating in region 2. The global environment is better off than under scenario 1 . a., and even improves initially. A comparison between Figures 2 and 5 shows that now the environment in region 2 is better off as well. Because of the technology strategy in region 1, its initial welfare is lower than in region 2, as is shown in Figure 6. However, after time period 12 the positions are reversed, and a maximum difference is reached in time period 38. Finally, Figure 7 shows that the trade pattern is asymmetric and much more irregular now. Domestic consumption of commodity $2\left(C_{22}\right)$ is decreasing from time 0 on, and is substituted by importing commodity $1\left(C_{21}\right)$. This is the consequence of changes in relative prices of the commodities, as shown

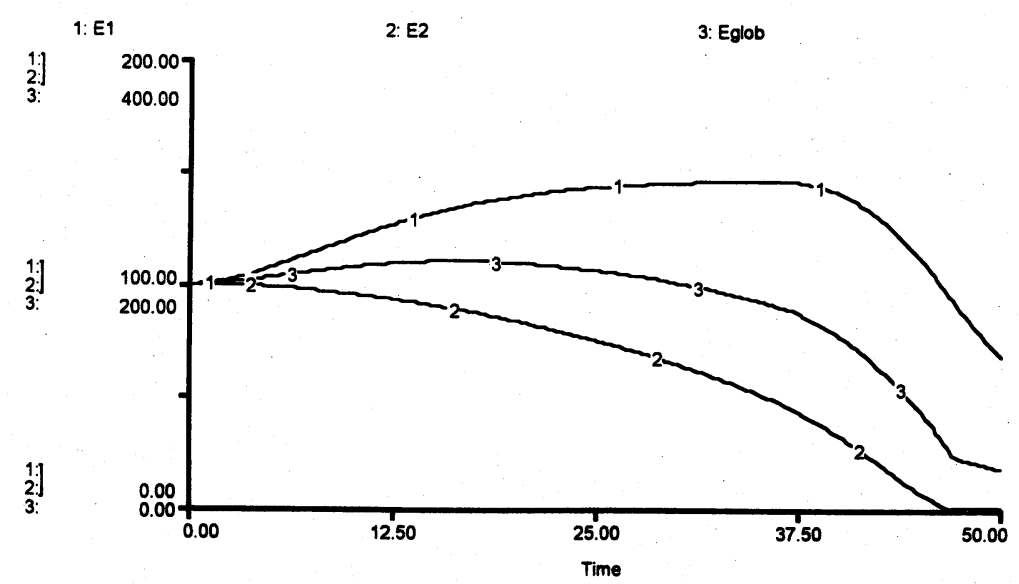

Figure 5. Scenario 1. b : Regional and global environmental quality $\left(E_{i}\right.$ and $\left.E_{g l o b}\right)$. 
van den Bergh and Nijkamp

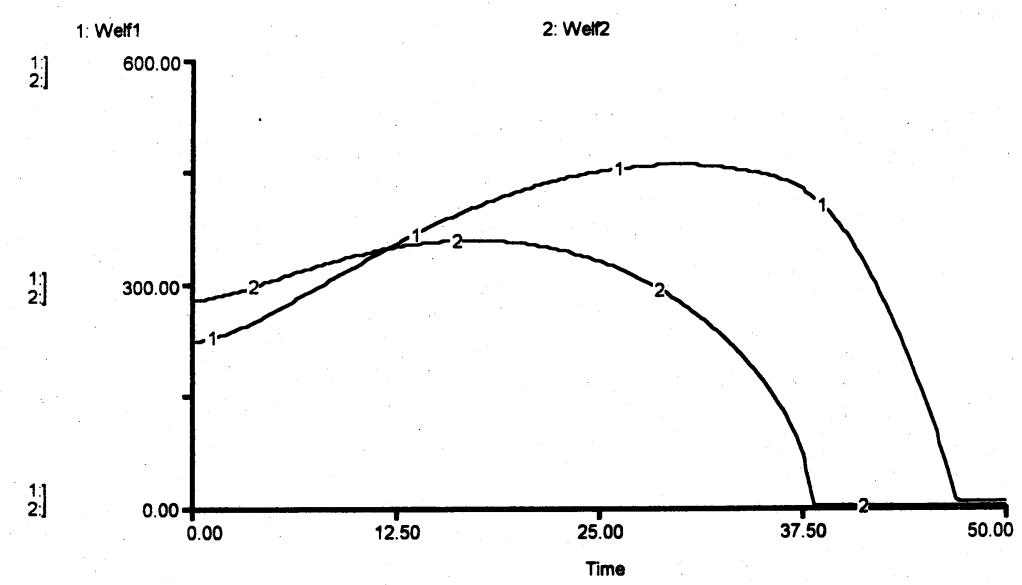

Figure 6. Scenario 1. b : Regional welfare indexes $\left(\operatorname{Welf}_{i}\right)$.

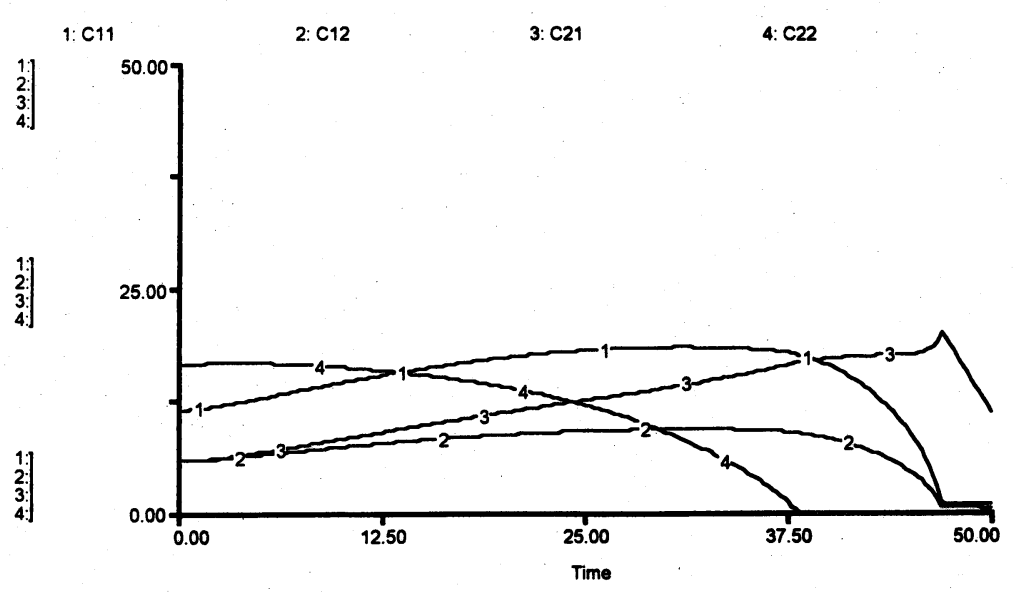

Figure 7. Scenario 1. b : Consumption $\left(C_{i i}\right.$ and $\left.C_{i j}\right)$ and trade $\left(C_{i j}\right)$.

in Figure 8. In region 1 the domestic consumption of commodity $1\left(C_{11}\right)$ can increase because of the favourable development of environmental quality, while the moderately increasing import of commodity $2\left(C_{12}\right)$ is the net result of the sharp increase of buying power of region 1 and the increase in the relative price of commodity 2 .

\section{Ad 1. c. Environmental policy in a homogeneous world}

The introduction of an environmental tax $\left(t_{1}\right)$ on the use of natural resource materials in the production in region 1 means that the relative prices of commodities are affected (Figure 9). However, since it does not affect the resource efficiency of materials inputs, and since there is no alternative way of producing, the dynamic effects are missing. The only effect here is a shift of income and welfare (Figure 10), via changes in trade (Figure 11). This is all based, 
Growth, Trade and Sustainability in the Spatial Economy

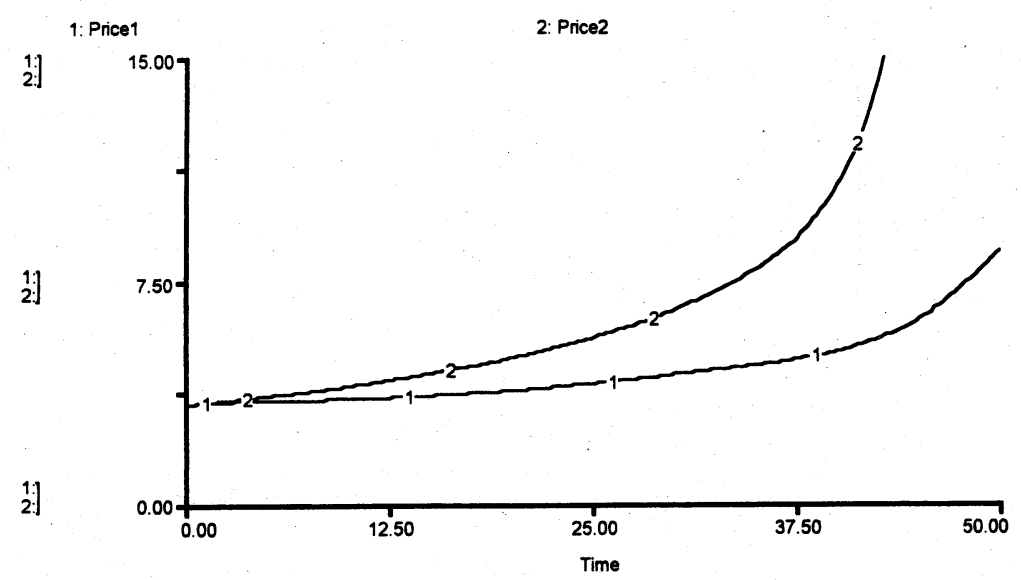

Figure 8. Scenario 1. b : Prices of regional outputs (Price ${ }_{i}$ ).

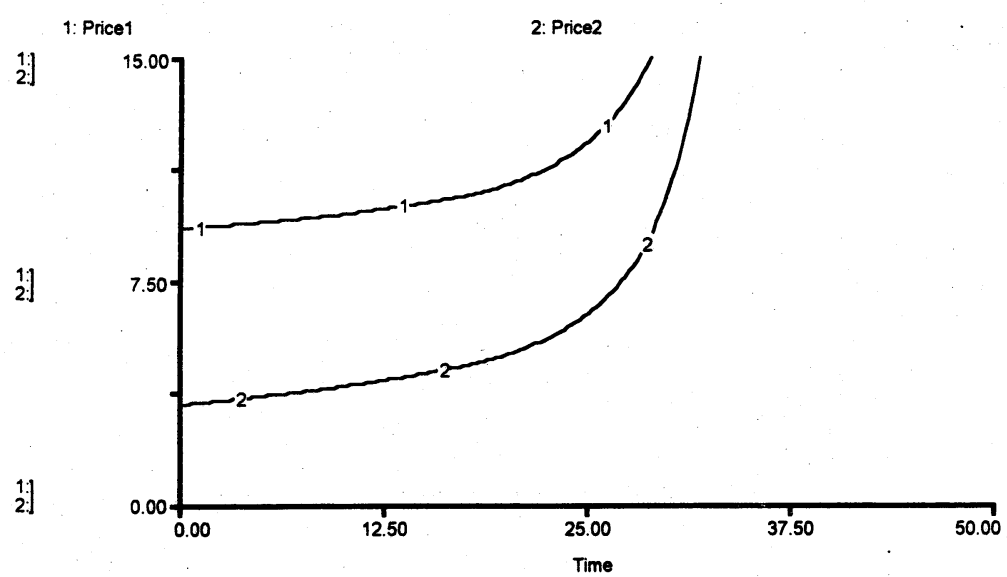

Figure 9. Scenario 1. c : Prices of regional outputs $\left(\right.$ Price $\left._{i}\right)$.

of course, on implicit assumptions regarding the international markets, in particular the absence of substitutes for commodity 1 .

\section{Ad 2. a. Plain growth in a heterogeneous world}

In this and the following two scenarios the starting point is a heterogeneous system of regions with regard to the production structure. This is formalized by reciprocal sets of elasticity of substitution coefficients in the Cobb-Douglas production functions. This is reflected by the patterns in Figure 12, where region 1 is less able to increase its production than region 2. Therefore is uses less resources and causes less environmental damage, and can longer sustain its local environment than region 2. This is reflected by relative prices in Figure 13, where initially region 2 has a price advantage, since it can produce more with a certain 
van den Bergh and Nijkamp

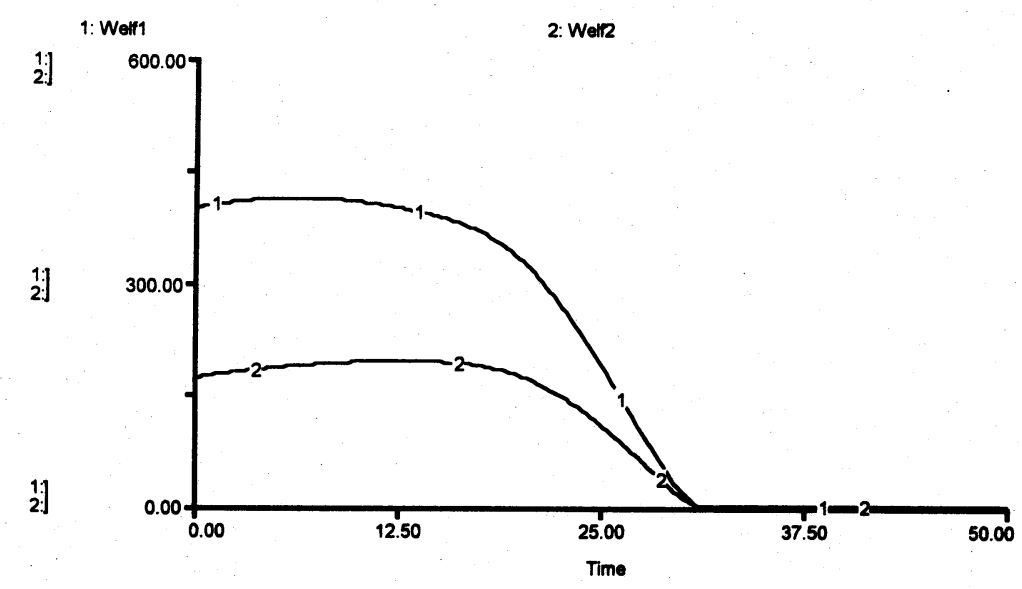

Figure 10. Scenario 1. c : Regional welfare indexes (Welf ${ }_{i}$.

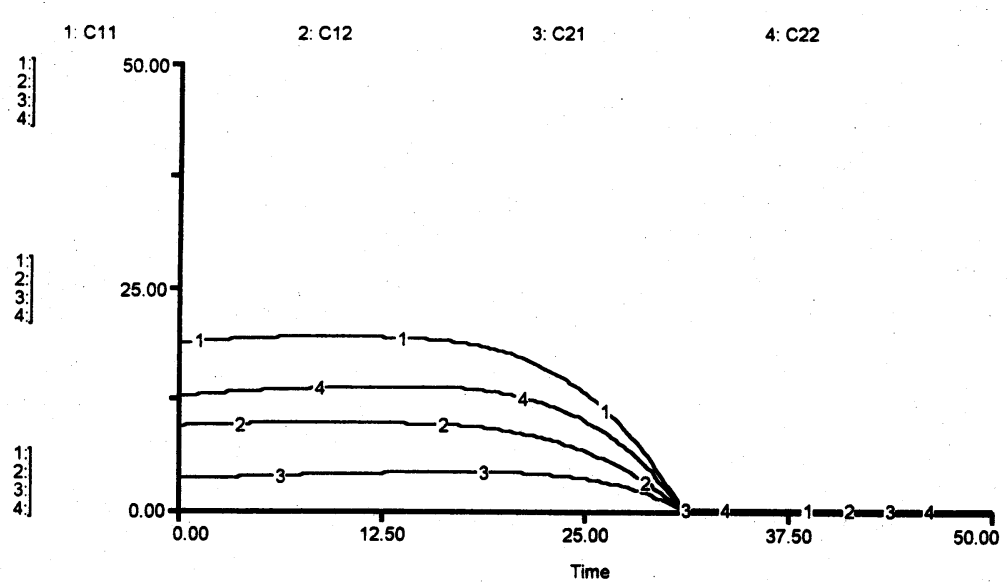

Figure 11. Scenario 1. c : Consumption $\left(C_{i i}\right.$ and $\left.C_{i j}\right)$ and trade $\left(C_{i j}\right)$.

endowment of natural resources, but the unsustainability of this region is reflected by the sharp increase through the price curve of region 1.

Ad 2. b. Environmental technology in a heterogeneous world

This scenario is chosen for comparison with scenario 2. c. In this case, as in scenario 1. b, technological progress, related to natural resource materials efficiency in production, causes an improvement toward a more sustainable development, not only in region 1 but also in region 2 , via the global environmental effect, and via trade. The comparison between scenarios $2 . \mathrm{b}$ and $2 . \mathrm{c}$ is discussed below.

Ad 2. c. Technology diffusion in a heterogeneous world 
Growth, Trade and Sustainability in the Spatial Economy

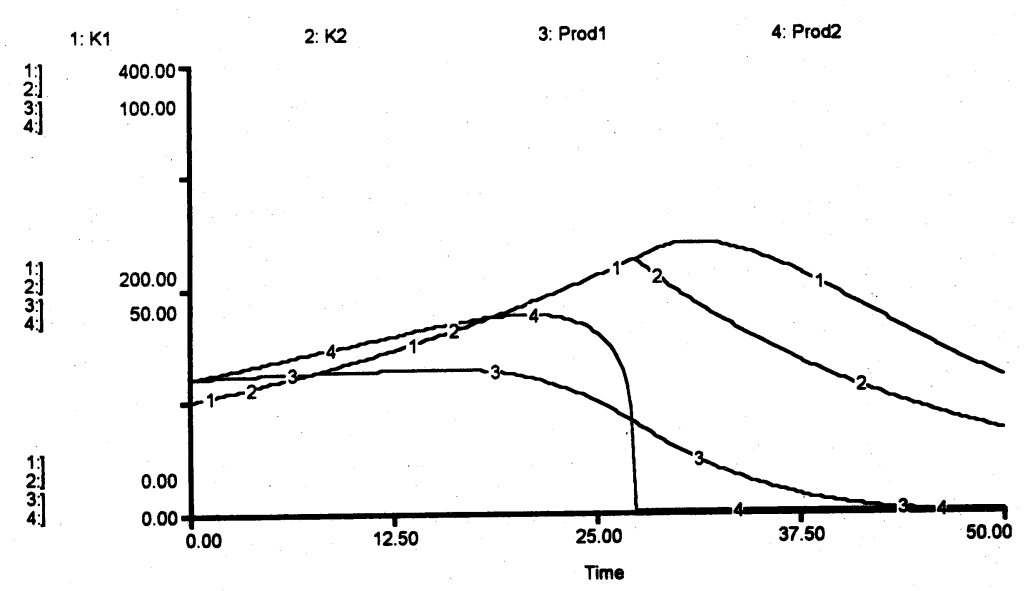

Figure 12. Scenario 2. a : Actors $\left(K_{i}\right)$ and production $\left(Q_{i}=\operatorname{Prod}_{i}\right)$.

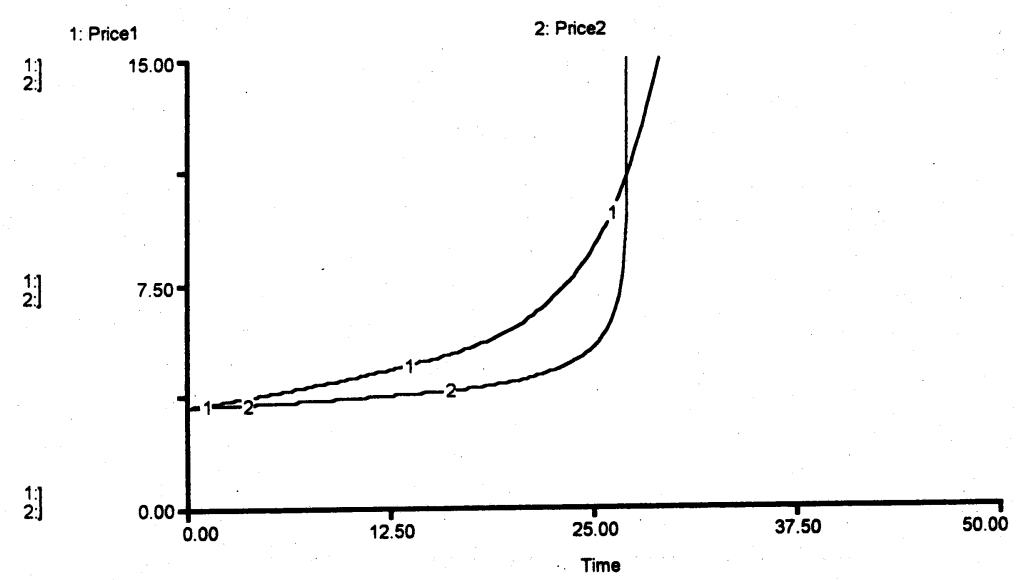

Figure 13. Scenario 2. a : Prices of regional outputs $\left(\right.$ Price $\left._{i}\right)$.

Here the furthering of sustainability in region 2 is not only occurring via the mechanism outlined above, but also via diffusion of technology. Region 2 is supposed to catch up, with a four-year delay, with the technology of region 1. In Figure 14 the difference between the two scenarios for the environmental quality in region 2 is shown. Resource materials can now be used increasingly more efficiently in region 2 as well. The differential effect over time on the global environment is shown in Figure 15, and for region 1's environment in Figure 16. ${ }^{2}$ Finally, the welfare indicators for both regions are shown in Figures 17 and 18 for scenario $2 . \mathrm{b}$ and 2. c, respectively. Whereas in scenario 2 . b region 1 ends up with higher welfare, under scenario 2 . c region 2 always has higher welfare. This can be explained by the

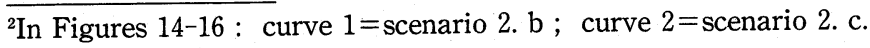




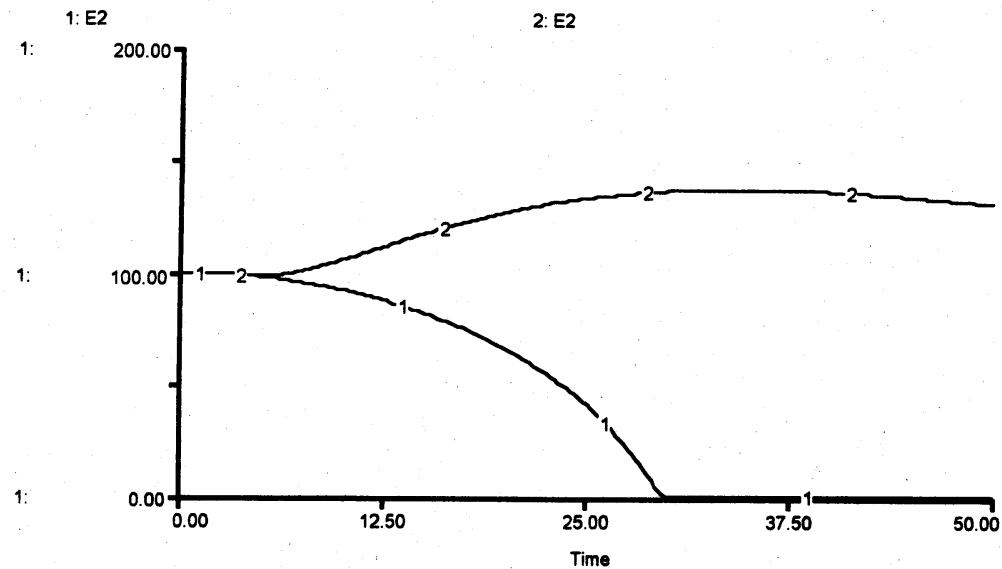

Figure 14. Comparison of environmental quality in region $2\left(E_{2}\right)$ under different scenarios : $1=$ scenario 2 . $\mathrm{b}$ and $2=$ scenario $2 \mathrm{c}$.

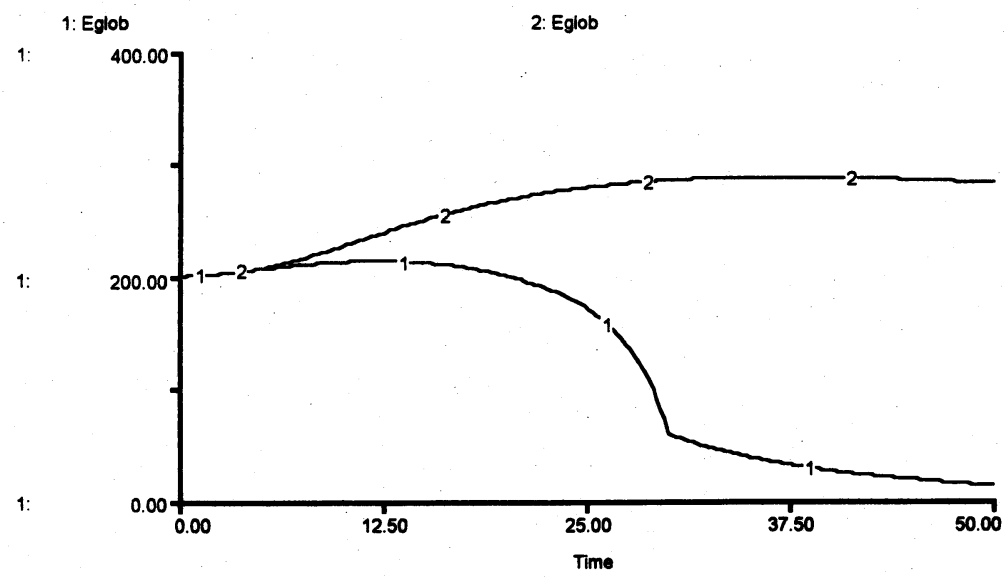

Figure 15. Comparison of global environmental quality $\left(E_{\text {glob }}\right)$ under different scenarios : $1=$ scenario 2 . $\mathrm{b}$ and $2=$ scenario $2 \mathrm{c}$.

fact that it profits from the diffusion of technology, without having to pay for it, as opposed to region 1, where the beneficial effect is without delay, but also at the cost of sacrificing scarce output.

\section{Conclusions and Further Research}

The results here are merely illustrative of the type of qustions to be addressed in the context of spatial sustainable economic development, based on the use of formal medelling procedures. The aim was, rather than to show doomsday or optimistic scenarios-which can never be tested anyway-to show the impact of spatial disaggregation and trade in the context 


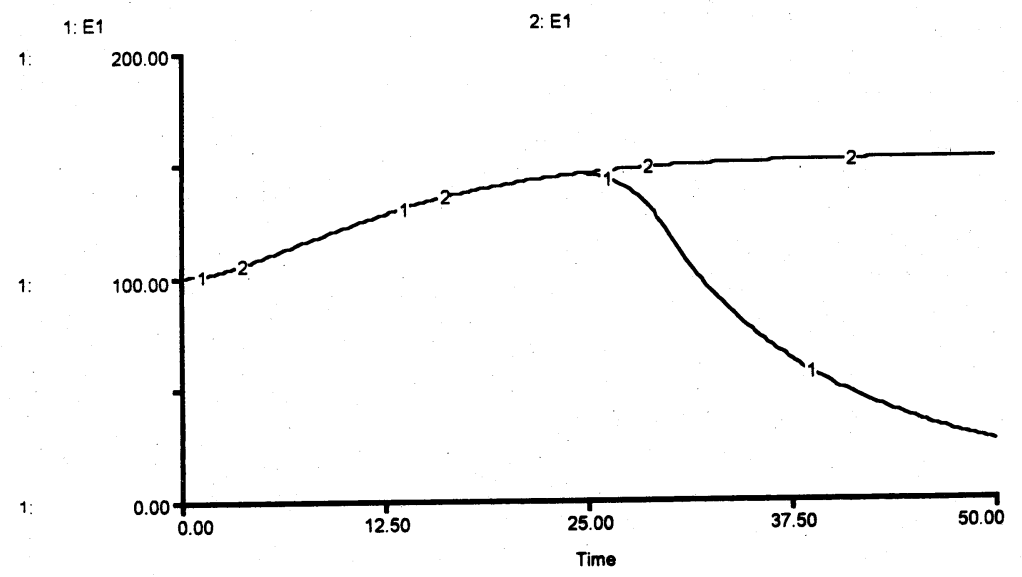

Figure 16. Comparison of environmental quality in region $1\left(E_{1}\right)$ under different scenarios : $1=$ scenario 2 b and $2=$ scenario 2 c.

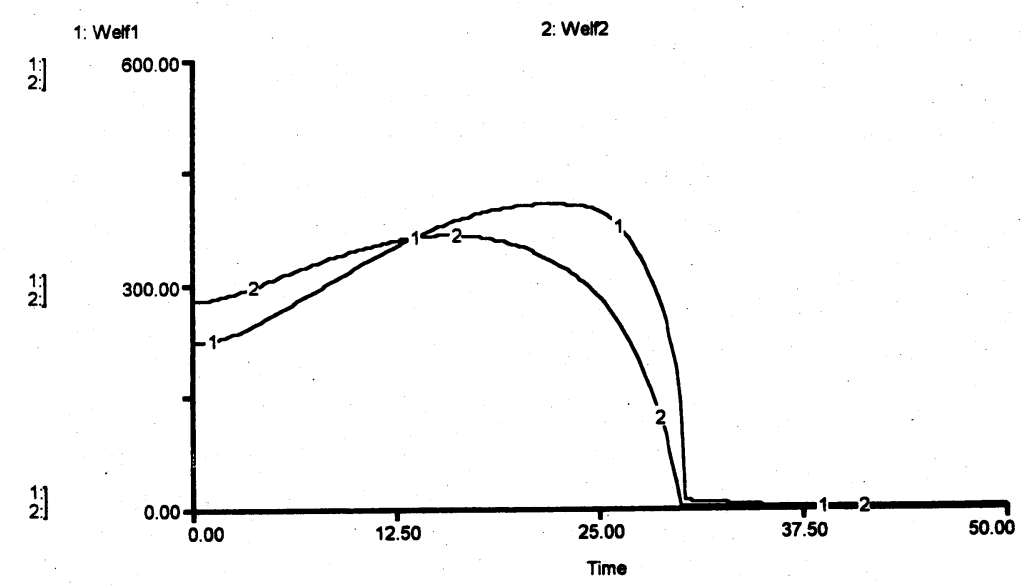

Figure 17. Scenario 2. b : Comparison of regional welfare indicators (Welf ${ }_{i}$ ).

of economic growth, given technological progress and diffusion, and environmental taxation. Many issues have not been dealt with yet, but can easily be included here. Furthermore, the evaluation of the different outcomes is a separate task, in which one can play around with different objectives, for instance, allowing for concern for future generations, or adopting a planner's perspective, concerned with maximization of some social welfare function, including externalities. One has to notice, however, that the problem of choosing a social evaluation criterion is even more complicated here than in a non-spatial setting, which is caused by the fact that one has to undertake then also an aggregation of regional variables, in particular welfare. 


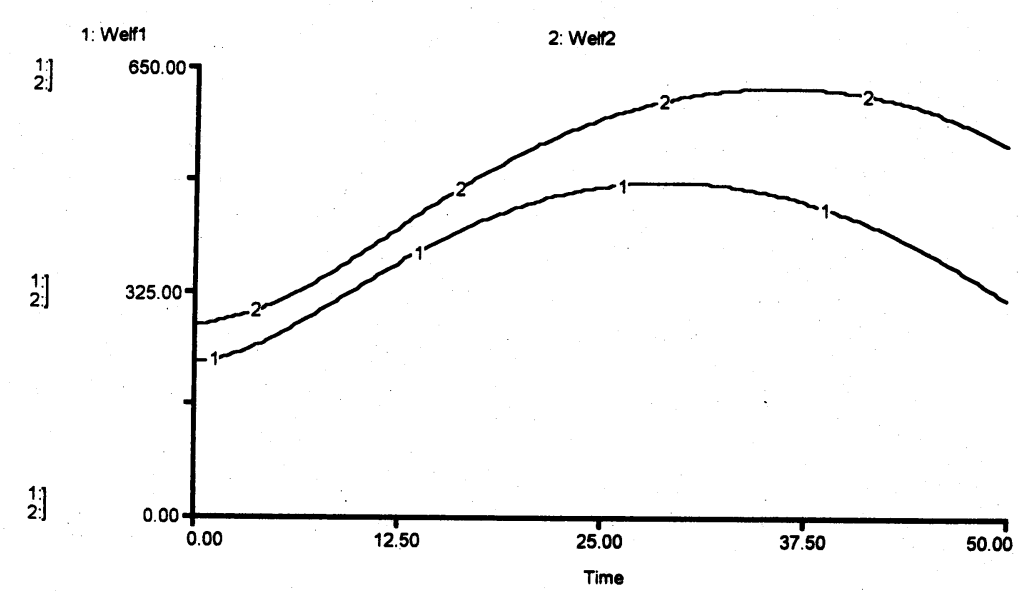

Figure 18. Scenario 2. c : Comparison of regional welfare indicators $\left(\right.$ Welf $\left._{i}\right)$.

Future work may focus on either theoretical generalizations, increasing realism of environmental processes, spatial processes, increased heterogeneity of regions, policy coordination issues, and multiple regions. The theoretical work is much restricted by the fact that the dynamic representation of the system is now already based on 5 differential equations, in which case a technique like optimal control theory is likely to generate unsolvable models. Increasing environmental realism may involve that resource and pollution issues are disaggregated as well as integrated, or alternatively, that peculiar ecological dynamics such as arising from species interactions or complex ecosystems are included. More attention for spatial processes can involve explicit treatment of the link between trade, trasport and environment. Dealing with heterogeneity of regions can involve specific treatment of the unique production structure, the growth capacity, natural resource endowments, environmental resilience, preferences, human capital or technology. Furthermore, policy coordination is a very important topic, on the level of both sub-national regions and countries. Finally, multi-dimensional elaborations do not seem immediately necessary for increasing our understanding of spatial sustainability. Because the potential to learn from two-regional studies is not yet exhausted.

Annex. List of Variables ( $i$ denotes region, $i=1,2)$

Stock variables

$K_{i}=$ actors input in production (capital, labour),

$T=$ accumulated research and development,

$E_{i}=$ indicator of state of the environment in region $i$, 


\section{Flow variables}

$Q_{i}=$ production,

$P_{i}=$ price of produced goods in region $i$,

$I_{i}=$ investment in $K_{i}$,

$I_{R \& D, 1}=$ research and development outlays in region 1 ,

$T_{d}=$ diffusion of technology from region 1 to 2 ,

$C_{i j}=$ consumption of commodity $j$ in region $i$,

$R_{i}=$ resource materials use in production,

$E_{\text {glob }}=$ global environmental indicator,

$W_{i}=$ welfare in region $i$,

\section{Parameters}

$a, b=$ production function elasticities (region 1 ),

$c, d=$ production function elasticities (region 2),

$C_{c}=$ carrying capacity of the regional environments,

$g=\mathrm{ex}$ ante net growth rate of actors,

$o_{1}=$ trade indicator for openness region 1 ,

$t_{i}=$ environmental taxation,

\section{Functions}

$D_{i}\left(K_{i}\right)=$ depreciation of capital dependent on the capital stock, $r=$ intrinsic regeneration rate of regional environments,

$\operatorname{MAX}()=$, function which generates the maximum of two inputs, $\operatorname{MIN}()=$, function which generates the mimimum of two inputs,

\section{References}

Alcamo, J., R. Shaw and L. Hordijk (eds), 1990, The Rains Model of Acidification: Science and Strategies in Europe. Kluwer Academic Publishers, Dordrecht.

Anderson, Å. E. and R. E. Kuenne 1986, Regional economic dynamics, in P. Nijkamp (ed), Handbook of Regional and Urban Economics, 201-253, vol. 1, North-Holland, Amsterdam.

Anderson, K. and R. Blackhurst (eds), 1992, The Greening of World Trade Issues. Harvester Wheatsheaf, New York.

Beinat, E., 1995, Multiattribute Value Functions For Environmental Management. Ph. D. dissertation, Free University, Thesis Publishers/Tinbergen Institute, Amsterdam.

Bergh, J. C. J. M. van den and P. Nijkamp, 1991, A general dynamic economic-ecological model for regional sustainable development, Journal of Environmental Systems, vol. 20, 89-214.

Bergh, J. C. J. M. van den and P. Nijkamp (eds), 1994, Sustainability, resources and region, The Annals of Regional Science, vol. 28(1), special issue. 
Bovenberg, A. L. and S. A. Smulders, 1994, Environmental policy in a two-sector endogenous growth model, in Proceedings Workshop Quantitative Economics and Environmental Policy, OCFEB, Erasmus University, Rotterdam.

Breheny, M. J., 1992, Sustainable development and urban form, European Research in Regional Science, vol. 2, Pion, London.

Common, M, and C. Perrings, 1992, Towards an ecological economics of sustainability, Ecological Economics, vol. 6, 7-34.

Despotakis, V. K., 1991, Sustainable Development Planning Using Geographical Information Systems, Ph. D. dissertation, Free University, Amsterdam.

Dasgupta, P. S. and G. M. Heal, 1979, Economic Theory and Exhaustible Resources, Cambridge University Press, Cambridge.

Dosi, C., and T. Tomasi (eds), 1994, Nonpoint source pollution regulation : Issues and Analysis, Kluwer Academic Publ., Dordrecht.

Erdman, G., 1993, Evolutionary economics as an approach to environmental problems, in H. Giersch (ed), Economic Progress and Environmental Concerns, Springer-Verlag, Berlin.

Faber, M, and J. L. R. Proops, 1990, Evolution, Time, Production and the Environment, Springer-Verlag, Heidelberg.

Gradus, R. and S. A. Smulders, 1993, The trade-off between environmental care and long-term growth : Pollution in three proto-type growth models, Journal of Economics, vol. 58, 25-52.

Hartwick, J. M., 1997, Intergenerational equity and the investing of rents from exhaustible resources, American Economic Review, vol. 67, 972-974.

Herwijnen, M. van, R, Janssen and P. Nijkamp, 1993, A multi-criteria decision support model and geographic information system for sustainable development planning of the Greek Islands, Project Appraisal, vol. 8, 9-22.

Holling, C. S., 1986, The resilience of terrestrial ecosystems : Local surprise and global change, in W. C. Clark and R. E. Munn (eds), Sustainable Development of the Biosphere, Ch. 16, Cambridge University Press, Cambridge.

Holling, C. S., 1994, New science and new investments for a sustainable biosphere, in, A, M. Jansson, M. Hammer, C. Folke and R. Costanza (eds). Investing in Natural Capital : The Ecological Economics Approach Sustainability, Island Press, Washington D. C.

Janssen, R. and P. Rietveld, 1990, Multicriteria analysus and GIS ; An application to agricultural land use in the Netherlands, in H. J. Scholten and J. C. H. Stillwell (eds), Geographical Information Systems and Urban and Regional Planning, Kluwer Academic Publishers, Dordrecht.

Klaasen, G., 1995, Trading Sulfur Emission Reduction Commitments in Europe : A Theoretical and Empirical Analysis, Ph. D. Dissertation, IIASA, Laxenburg.

Klijn, F. (ed), 1994, Ecosystem Classification for Environmental Management, Kluwer Academic Publishers, Dordrecht.

Markusen, J. R., E. R. Morey and N. D. Olewiler, 1993, Environmental policy when market structure and plant locations are endogenous, Journal of Environmental Economics and Management, vol. 24, 69-86.

Maxwell, T. and R. Costanza, 1994, Spatial ecosystem modeling in a distributed computational environment, in J. C. J. M. van den Bergh and J. van der Straaten (eds). Toward Sustainable Development : Concepts, Methods and Policy, Island Press, Washington D. C., 111-138.

Meadows, D. H., D. L. Meadows, J, Randers and W. W. Behrens III, 1972, The Limits to Growth, Universe Books, New York.

Meadows, D. H., D. L. Meadows and J. Randers, 1992, Beyond the Limits : Confronting Global Collapse ; Envisioning a Sustainable Future, Chelsea Green Publishing Co., Post Mills.

Musu, I., 1994, On sustainable endogenous growth, Nota di Lavoro 11.94, Fondazione Eni Enrico Mattei, 
Milano.

Nijkamp, P. and A. Perrels, 1994, Sustainable Cities in Europe, Earthscan, London.

Nordhaus, W. D., 1973, World Dynamics : Measurement without data, Economic Journal, vol. 83, 1156-1183.

Nordhaus, W. D., 1990, To slow or not to slow : The economics of the greenhouse effect, Economic Journal, vol. 101, 920-937.

Nordhaus, W. D., 1992, Lethal Model 2 : The limits to growth revisited, Brooking Papers on Economic Activity, vol. 2, 1-59.

Nordhaus, W. D., 1993, How much should we invest in preserving our current climate, in : H. Giersch (ed), Economic Progress and Environmental Concerns, Springer-Verlag, Berlin.

Pearce, D. W., and R. K. Turner, 1990, Economics of Natural Resources and the Environment, Harvester Wheatsheaf, New York.

Perrings, C., 1991, Ecological sustainability and environmental control, Structural Change and Economic Dynamics, vol. 2, 275-295.

Ploeg, F. van der, and A. J. de Zeeuw, 1992, International aspects of pollution control, Environmental and Resource Economics, vol. 2, 117-139.

Roson, R. (ed), 1994, Transportation and General Equilibrium Models, Proceedings of an International Workshop, Venice, May 1993.

Russell, C. S. and J. F. Shogren (eds), 1993. Theory, Modeling and Experience in the Management of Non-point Source Pollution, Kluwer Academic Publ., Dordrecht.

Siebert, H., 1985, Spatial aspects of environmental economics,in A. V. Kneese and J. L. Sweeney (eds), Handbook of Natural Resource and Energy Economics, vol. 1, North-Holland, Amsterdam.

Siebert, H., 1987, Economics of the Environment : Theory and Policy, 2nd ed. Springer-Verlag, Berlin.

Smulders, S. A., 1994, Growth, Market structure and the Environment : Essays on the Theory of Endogenous Economic Growth, Ph. D. Thesis, Tiburg University (KUB), Tiburg.

Tahvonen, O. and J. Kuuluvainen, 1991, Optimal growth with renewable resources and pollution, European Economic Review, vol. 35, 650-661.

Tahvonen, O. and J. Kuuluvainen, 1993, Economic growth, pollution and renewable resources, Journal of Environmental Economics and Management, vol. 24, 101-118.

Toman, M. A., J. Pezzey, and J. Krautkraemer, 1994, Neoclassical economic growth theory and sustainability, in D. Bromley (ed). Handbook of Environmental Economics, Blackwell, Oxford.

Verhoef E. T., and J. C. J. M. van den Bergh, 1995, A Spatial Price Equilibrium model for environmental policy analysis of mobile and immobile sources of pollution, in J. C. J. M. van den Bergh, P. Nijkamp and P. Rietveld (eds), Recent Advances in Spatial Equlibrium Modelling, Springer-Verlag, forthcoming. 